\title{
Atividade leishmanicida de Aspidosperma nitidum Benth. Ex Müll. Arg
}

\author{
Leishmanicidal activity of Aspidosperma nitidum Benth. Ex Mülll. Arg \\ Actividad leishmanicida de Aspidosperma nitidum Benth. Ex Müll. Arg
}

\section{Resumo}

O tratamento medicamentoso da leishmaniose pode acarretar várias reações adversas e já foram encontrados isolados de Leishmania resistentes a terapêutica. Neste cenário, torna-se imprescindível a busca de alternativas terapêuticas e alcaloides, isolados de plantas pertencentes ao gênero Aspidosperma, têm se mostrado promissores como antiparasitário. $\mathrm{O}$ presente estudo avaliou a atividade antipromastigota, amastigota e citotoxicidade do extrato e frações pertencentes a $A$. nitidum. O extrato etanólico das cascas (EE) foi obtido por maceração e submetido a partição ácido:base, sendo obtidas as frações FN e FA. Além disso, o EE foi submetido ao fracionamento sob refluxo, obtendo-se as frações FrHEX, FrDCL, FrAcOEt e FrMeOH. A atividade antipromastigota em L. amazonensis e citotoxicidade para macrófagos foram avaliadas através do ensaio de viabilidade (MTT). Após a invasão dos macrófagos pelo parasito, realizou-se o tratamento com diferentes concentrações das amostras por $72 \mathrm{~h}$, seguida de fixação e coloração das amostras e leitura em microscópio óptico. Somente a FrDCL mostrou-se moderadamente ativa contra promastigota $\left(\mathrm{CI}_{50}=105,7 \pm 1,12 \mu \mathrm{g} / \mathrm{mL}\right)$. No entanto, o EE $\left(\mathrm{CI}_{50}=23,87 \pm 0,87 \mu \mathrm{g} / \mathrm{mL}\right)$ e FA $\left(\mathrm{CI}_{50}=18,5 \pm 0,94 \mu \mathrm{g} / \mathrm{mL}\right)$ mostraram-se ativos contra amastigota, enquanto que na FrDCL $\left(\mathrm{CI}_{50}=204,5 \pm 0,71 \mu \mathrm{g} / \mathrm{mL}\right)$ e FrHEX $\left(\mathrm{CI}_{50}=143,0 \pm 0,82 \mu \mathrm{g} / \mathrm{mL}\right)$ observou-se atividade moderada. Quando se relaciona a citotoxicidade das amostras a atividade antiamastigota, observa-se que o $\mathrm{EE}\left(\mathrm{CC} \mathrm{C}_{50}=\right.$ $491,8+1,86 \mu \mathrm{g} / \mathrm{mL} ; \mathrm{IS}=21)$ parece ser mais promissor que a FA $\left(\mathrm{CC}_{50}=209,1+1,7 \mu \mathrm{g} / \mathrm{mL} ; \mathrm{IS}=11\right)$. Em síntese, a $A$. nitidum mostrou-se promissora como leishmanicida.

Palavras-chave: Aspidosperma; Leismania; Extrato; Fração.

\begin{abstract}
Drug treatment for leishmaniasis can lead to several adverse reactions, and therapy-resistant isolates of Leishmania have already been found. In this scenario, the search for therapeutic alternatives and alkaloids, isolated from plants belonging to the genus Aspidosperma, has proved to be promising as antiparasitic. The present study evaluated the antipromastigote, amastigote and cytotoxicity activity of the extract and fractions belonging to A. nitidum. The ethanol extract of the shells (EE) was obtained by maceration and submitted to an acid:base partition, with the FN and FA fractions being obtained. In addition, the EE was subjected to fractionation under reflux, obtaining the fractions FrHEX, FrDCL, FrAcOEt and FrMeOH. The antipromastigote activity in L. amazonesis and cytotoxicity to macrophages were evaluated using the viability test (MTT). After the invasion of macrophages by the parasite, the treatment was performed with different sample concentrations during 72 hours, followed by samples staining and reading under the optical microscope. Only FrDCL was moderately active against promastigotes $\left(\mathrm{IC}_{50}=105.7 \mu \mathrm{g} / \mathrm{mL}\right)$. However, $\mathrm{EE}\left(\mathrm{IC}_{50}=23.87\right.$
\end{abstract}


$\mu \mathrm{g} / \mathrm{mL})$ and FA $\left(\mathrm{IC}_{50}=18.5 \mu \mathrm{g} / \mathrm{mL}\right)$ were shown to be active against amastigote, whereas in FrDCL (IC ${ }_{50}=204.5$ $\mu \mathrm{g} / \mathrm{mL})$ and FrHEX $\left(\mathrm{IC}_{50}=143.0 \mu \mathrm{g} / \mathrm{mL}\right)$ moderate activity was observed. When samples cytoxicity is related to antiamastigote activity, the $\mathrm{EE}\left(\mathrm{CC}_{50}=491.8 \mu \mathrm{g} / \mathrm{mL}\right.$; IS $\left.=21\right)$ seems to be more promising than the $\mathrm{FA}\left(\mathrm{CC}_{50}=209.1\right.$ $\mu \mathrm{g} / \mathrm{mL}$; IS = 11). In summary, A. nitidum is promise as a leishmanicide.

Keywords: Aspidosperma; Leismania; Extract; Fraction.

\section{Resumen}

El tratamiento farmacológico de la leishmaniasis puede provocar varias reacciones adversas y ya se han encontrado cepas de Leishmania resistentes al tratamiento. En este escenario, la búsqueda de alternativas terapéuticas y alcaloides, aislados de plantas pertenecientes al género Aspidosperma, ha demostrado ser prometedora como antiparasitario. El presente estudio evaluó la actividad antipromastigota, amastigota y citotoxicidad del extracto y fracciones pertenecientes a $A$. nitidum. El extracto etanólico de las cáscaras (EE) se obtuvo por maceración y sometido a un reparto ácido: base, obteniéndose las fracciones FN y FA. Además, el EE se sometió a fraccionamiento a reflujo, obteniendo las fracciones FrHEX, FrDCL, FrAcOEt y FrMeOH. La actividad antipromastigota en Leishmania (Leishmania) amazonensis y la citotoxicidad para los macrófagos se evaluaron mediante la prueba de viabilidad (MTT). Tras la invasión de los macrófagos por el parásito, se realizó el tratamiento con diferentes concentraciones de las muestras durante $72 \mathrm{~h}$, seguido de la fijación y tinción de las muestras y lectura al microscopio óptico. Sólo FrDCL fue moderadamente activo contra promastigote $\left(\mathrm{CI}_{50}=105,7 \pm 1,12 \mu \mathrm{g} / \mathrm{ml}\right)$. Sin embargo, $\mathrm{EE}\left(\mathrm{CI}_{50}=23,87 \pm 0,87 \mu \mathrm{g} / \mathrm{mL}\right)$ y FA $\left(\mathrm{CI}_{50}=18,5 \pm 0,94 \mu \mathrm{g} /\right.$ $\mathrm{mL})$ mostraron ser activos contra amastigote, mientras que en FrDCL $\left(\mathrm{CI}_{50}=204,5 \pm 0,71 \mu \mathrm{g} / \mathrm{mL}\right)$ y FrHEX $\left(\mathrm{CI}_{50}=\right.$ 143,0 $\pm 0,82 \mu \mathrm{g} / \mathrm{ml}$ ) se observó una actividad moderada. Cuando la citotoxicidad de las muestras se relaciona con la actividad antiamastigota, se observa que el EE $\left(\mathrm{CC}_{50}=491,8+1,86 \mu \mathrm{g} / \mathrm{mL}\right.$; IS $\left.=21\right)$ parece ser más prometedor que el FA $\left(C_{50}=209,1+1,7 \mu \mathrm{g} / \mathrm{mL}\right.$; IS = 11). En resumen, A. nitidum se ha mostrado prometedor como leishmanicida.

Palabras clave: Aspidosperma; Leismania; Extracto; Fracción.

\section{Introdução}

As leishmanioses são um grupo de doenças causadas por protozoários, pertencentes ao gênero Leishmania e com mais de 20 espécies que podem ocasionar a doença no homem. Estes parasitas são transmitidos aos seres humanos pela picada do flebotomíneo fêmea infectado, ocasionando três formas principais de leishmaniose: cutânea, visceral ou calazar e mucocutânea (WHO, 2019).

Em dezembro de 2019, 52 países endêmicos da VL (68\%) notificaram a doença, sendo que mais de $90 \%$ dos casos ocorreram no Brasil, Etiópia, Índia, Quênia, Somália, Sudão do Sul e Sudão. Em relação a leishmaniose cutânea (LC), em 11 países ocorrem 88\% dos casos notificados, dentre estes estão: Afeganistão, Argélia, Bolívia, Brasil, Colômbia, República Islâmica do Irã, Iraque, Paquistão, Peru, República Árabe da Síria e Tunísia (WHO, 2019).

Para o tratamento da leishmaniose, em geral, é utilizado o antimoniato de N-metilglucamina e alternativamente o isotionato de pentamidina e a anfotericina B. A pentamidina é mais cara que o antimonial, entretanto, o custo global do tratamento com antimonial é mais elevado, pois possui despesas indiretas, relacionadas a insumos hospitalares, eventuais necessidades de afastamento do trabalho ou internação (Naiff, et al., 1999; Neves, et al., 2011). Outros fármacos utilizados para o tratamento da LC são miltefosina, azitromicina, itraconazol, cetoconazol, alopurinol, paramomicina e pentoxifilina (Lima, et al., 2007; Neves, et al., 2011).

Várias reações adversas e efeitos tóxicos do antimonial já foram notificadas, tais como: toxicidades cardíaca (Chulay, et al., 1985; Chulay, et al., 1988), hepática, pancreática, renal e do sistema músculo-esquelético (Marsden, 1994; Croft \& Yardley, 2002). Alguns eventos são dose e tempo dependentes (Franke, et al., 1990). Outro aspecto negativo, relacionado ao tratamento da leishmaniose, a ser considerado é a falha terapêutica, bem como os casos de recorrências (Padrón-Nieves \& Ponte-Sucre, 2015).

A resistência do parasito ao fármaco tem sido relacionada a diminuição intracelular da concentração do fármaco devido à superexpressão dos transportadores ABC (transportadores de cassetes de ligação ao ATP ou ATP-binding cassette transports; Blackmore, et al., 2001; Leslie, et al., 2005). O círculo H, descrito na Leishmania, é uma estrutura extracromossômica que contém genes para transportadores $\mathrm{ABC}$, sendo que o aumento de sua expressão tem sido associado à 
resistência aos fármacos (Padrón-Nieves \& Ponte-Sucre, 2015). Diante deste cenário, torna-se urgente a busca de alternativas terapêuticas, sendo as plantas medicinais importantes fontes de novos fármacos.

O alcaloide flavopereirina, isolado de Geissospermum vellosii mostrou-se promissor como leishmanicida. Também, o extrato etanólico obtido desta espécie e sua fração foram ativos contra a Leishmanina (Leishmania) amazonensis (Silva \& Silva, 2019). Alcaloides isolados de Aspidosperma ramiflorum foram ativos contra a Leishmania (L.) amazonensis (Ferreira, et al., 2004).

O presente estudo avaliou a atividade do extrato etanólico obtido de cascas de Aspidosperna nitidum, bem como frações que possuem alcaloides e outras frações, contra as formas promastigota e amastigota de $L$. (L.) amazonensis, além disso, avaliou o potencial citotóxico destas amostras, determinando sua seletividade.

\section{Metodologia}

\subsection{Obtenção do extrato, fracionamento e caracterização}

As cascas dos troncos da espécie A. nitidum foram coletadas em Genipaúba, localidade de Santa Bárbara do Pará (S 01 10' 946' W 048 11' 715'), herborizadas e incorporadas ao Herbário MG do Museu Paraense Emílio Goeldi, sob registro MG206608. A seguir, as cascas foram secas em estufa por sete dias, moídas e submetidas à maceração (7 dias). O extrato obtido foi submetido a partição ácido:base, sendo solubilizado em metanol e adicionado solução aquosa de ácido clorídrico a 3\%. Esta solução foi extraída com diclorometano, obtendo-se a fração de neutros (FN). A camada aquosa ácida foi alcalinizada com hidróxido de amônio $\left(\mathrm{NH}_{4} \mathrm{OH}\right)$ até potencial hidrogeniônico $(\mathrm{pH})$ 9, seguida de nova extração com diclorometano, sendo obtida uma camada aquosa alcalina e uma camada orgânica (fração de alcaloides).

$\mathrm{O}$ extrato e as frações obtidas foram submetidos à Cromatografia em Camada Delgada (CCD) em sílica gel, utilizando-se como fase móvel diclometano/acetato de etila/ácido fórmico (12:8:5,5), sendo visualizadas em luz Ultravioleta (UV) a $365 \mathrm{~nm}$ (nanometros) e reveladas com Dragendorff. Após, para identificação das substâncias isoladas foi utilizado método espectroscópico de Ressonância Magnética Nuclear de Hidrogênio (RMN $\left.{ }^{1} \mathrm{H}\right)$ apenas para a amostra que apresentasse manchas sugestivas de alcaloides.

Além do método de partição ácido-base, o extrato etanólico foi submetido à sistema sob refluxo. Ao extrato foi acrescentado solventes com polaridades crescentes (hexano, diclorometano, acetato de etila e metanol) e, em seguida, este foi aquecido $\left(40^{\circ} \mathrm{C}\right)$ sob refluxo por 20 minutos. O procedimento foi repetido por 3 vezes para cada solvente (Vale, et al., 2015), obtendo-se as seguintes frações: Fração hexano (FrHEX), Fração diclorometano (FrDCL), Fração acetato de etila (FrAcOEt) e Fração metanolica (FrMeOH).

Destacando-se que a metodologia desenvolvida neste estudo foi quantitativa, onde se realizou a coleta de dados quantitativos ou numéricos através do uso de medições de grandezas e por meio da metrologia obteve-se números com suas respectivas unidades. Estes métodos produzem conjuntos ou massas de dados que podem ser analisados através de técnicas matemáticas como é o caso das porcentagens, estatísticas e probabilidades, métodos numéricos, métodos analíticos e geração de equações e/ou fórmulas matemáticas aplicáveis a algum processo (Pereira, et al., 2018).

\subsection{Atividade leishmanicida}

A cepa de Leishmania (L.) amazonensis (MHOM/BR/2009/M26361) foi cedida pelo Instituto Evandro Chagas, Belém, Pará. E a seguir, as formas promastigotas desta espécie de Leishmania foram primeiramente cultivas em meio NNN (Novy-Nicolle-Mcneal) e posteriormente transferidas para o meio de crescimento RPMI (Roswell Park Memorial Institute medium) suplementado com $10 \%$ de soro fetal bovino desnaturado, penicilina G 10.000 UI (unidades internacionais)/mL 
(mililitros) e estreptomicina $10.000 \mu \mathrm{g}$ (microgramas)/mL e mantidas a $25^{\circ} \mathrm{C} \pm 1{ }^{\circ} \mathrm{C}$ através de passagens. Após o cultivo seguiu-se o ensaio de atividade antipromastigota e antiamastigota conforme será descrito a seguir.

No ensaio de atividade antipromastigota, promastigotas de $L$. (L.) amazonensis obtidas durante a fase logarítmica de crescimento, foram centrifugadas e tiveram sua concentração ajustada para $4 \times 10^{6}$ parasitos/100 $\mu \mathrm{L}$ (microlitros). Esta suspensão foi distribuída em placas de 96 poços que já continha as amostras a serem testadas em diferentes concentrações (200 a $3.125 \mu \mathrm{g} / \mathrm{mL}$ ) e, a seguir, a placa foi incubada durante 72 horas $(\mathrm{h}) / 26^{\circ} \mathrm{C}$. O controle negativo consistiu do parasito e meio de cultura e o controle positivo do parasito e anfotericina B ( 25 a $0.3906 \mu \mathrm{g} / \mathrm{mL})$. Após $72 \mathrm{~h}$ de incubação, foi adicionado MTT (brometo de 3-(4,5-dimetiltiazol-2-yl)- 2,5-difeniltetrazolium; $5 \mathrm{mg} / \mathrm{mL}$ ) em cada poço. Decorridas $4 \mathrm{~h}$ de incubação, adicionou-se dimetilsulfóxido (DMSO) e. a seguir, realizou-se leitura em leitor de microplacas (490 nm). A Concentração inibitória 50\% ( $\left.\mathrm{CI}_{50}\right)$ foi determinada por regressão linear (Graph Pad Prism versão 5.04). Os resultados foram classificados conforme os seguintes critérios: $\mathrm{CI}_{50} \leq 100 \mu \mathrm{g} / \mathrm{mL}$ - amostra ativa, $\mathrm{CI}_{50}$ entre 101 - $200 \mu \mathrm{g} / \mathrm{mL}$ - amostra moderamente ativa, e $\mathrm{CI}_{50} \geq 200 \mu \mathrm{g} / \mathrm{mL}$ - amostra inativa (Mota, et al., 2015).

No ensaio de atividade antiamastigota, macrófagos obtidos do peritônio de camundongos BALB/c (com concentração ajustada para $4 \times 10^{5}$ parasitos $/ 50 \mu \mathrm{L}$ ) foram inicialmente mantidos em meio RPMI 1640 suplementado e, a seguir adicionados em lamínulas circulares previamente colocadas nos poços de uma placa de 24 poços $\left(4 \times 10^{5}\right.$ células $\left./ 50 \mu \mathrm{L}\right)$. Após, promastigotas de $L$. (L.) amazonensis foram adicionadas $\left(4 \times 10^{6}\right.$ parasitos) aos poços desta placa. Depois de $4 \mathrm{~h}$ de incubação em estufa a $35{ }^{\circ} \mathrm{C} / 5 \%$ de $\mathrm{CO}_{2}$ (dióxido de carbono), foi realizada lavagem dos poços e, adicionado meio RPMI 1640 suplementado e as amostras testadas em diferentes concentrações com base na Concentração citotoxica $50 \%\left(\mathrm{CC}_{50}\right)$. Decorridas $72 \mathrm{~h}$ de incubação em estufa, as lamínulas circulares foram removidas dos poços, fixadas com metanol e coradas com Giemsa. As lamínulas foram observadas ao microscópio óptico e, a seguir, foi determinado o número de amastigotas por 100 macrófagos em cada lamínula (índice de infecção).

Ressaltando-se que todos procedimentos estão de acordo com os princípios éticos da experimentação animal. E o estudo foi aprovado pela à Comissão de Ética em pesquisa no uso de Animais do Instituto Evandro Chagas (CEUA) com parecer de aprovação n 29/2016/CEUA/IEC/SVS/MS.

\subsection{Ensaio de viabilidade celular}

A viabilidade celular foi determinada por MTT (Mosman, 1983). Macrófagos obtidos do peritônio de camundongos $\mathrm{BALB} / \mathrm{c}$ (concentração ajustada para $4 \times 10^{5}$ parasitos $/ 100 \mu \mathrm{L}$ ) foram distribuídos em placas de 96 poços e incubados a $35^{\circ} \mathrm{C}$ em estufa/ $5 \%$ de $\mathrm{CO}_{2}$ durante $24 \mathrm{~h}$. Após a incubação, os poços foram lavados e as células tratadas com as amostras testadas em diferentes concentrações (500 a 7,8125 $\mu \mathrm{g} / \mathrm{mL}$ ). Após $72 \mathrm{~h}$ de incubação, MTT foi adicionado $(5 \mathrm{mg} / \mathrm{mL}$ ) e as placas foram incubadas a $35^{\circ} \mathrm{C}$ em estufa com atmosfera de $5 \%$ de $\mathrm{CO}_{2}$ durante $4 \mathrm{~h}$. Depois deste período, DMSO foi adicionado a cada a poço para solubilizar os cristais de formazan. A leitura da densidade óptica (D.O.) das amostras foi realizada em leitor de microplacas $(490 \mathrm{~nm}$ ). A porcentagem de células viáveis (macrófagos) foi calculada, conforme fórmula adaptada de Ngure, et al. (2009) e a $\mathrm{CC}_{50}$ (Concentração Citotóxica 50\%) foi determinada por regressão linear (Graph Pad Prism versão 5.04). Na citotoxicidade para macrófagos peritoneais estabeleceu-se os seguintes critérios: menor ou igual a 100- muito tóxico; maior que 100 e menor que 500- moderadamente tóxico; Maior ou igual a 500- baixa toxicidade (Dolabela, 2007). O índice seletividade (SI) para a atividade antipromastigota e antiamastigota foi calculado baseado razão entre $\mathrm{CC}_{50}$ e $\mathrm{CI}_{50}$ (Reimão, 2009). 


\section{Resultados}

\subsection{Estudo fitoquímico}

O processo de extração utilizado neste estudo forneceu um rendimento de 5,1\% do extrato etanólico obtido das cascas de A. nitidum (EE). O fracionamento do EE, através do método de partição ácido-base, levou a obtenção das frações alcaloídica $(\mathrm{FA}$, rendimento $=29,25 \%)$ e de neutros $(\mathrm{FN}$, rendimento $=21,8 \%)$. Enquanto, a extração sob refluxo gerou as frações: hexânica (FrHEX, rendimento $=2,4 \%$ ), diclorometano (FrDCL, rendimento $=8,37 \%$ ), acetato de etila (FrAcOEt, rendimento $=18,6 \%)$ e metanólica $(\mathrm{FrMeOH}$, rendimento $=38,4 \%)$.

O EE e suas frações foram submetidas a análises por CCD, sendo observadas predominantemente manchas azuis, quando visualizadas em UV (365 nm). Visando verificar se esta fluorescência azul poderia estar relacionada aos alcaloides, as placas foram reveladas com reagente de Dragendorff, sendo observado manchas castanho-alaranjadas para o EE, FA e FrDCL.

$\mathrm{O}$ espectro de RMN de ${ }^{1} \mathrm{H}$ da fração FA demonstrou a presença de 23 sinais com deslocamentos químicos em $\delta \mathrm{H}$ 7,64, 7,61, 7,47, 7,46, 7,45, 7,41, 7,39, 7,38, 7,36, 7,33, 7,31, 7,30, 7,26, 7,19, 7,16, 7,12, 7,10, 7,08, 7,05, 6,96, 6,94, 6,91 e 6,89 .

\subsection{Atividade leishmanicida}

A atividade leishmanicida in vitro foi avaliada em formas promastigota e amastigota de L.(L.) amazonensis. A fração diclorometano mostrou-se moderadamente ativa contra a forma promastigota $\left(\mathrm{CI}_{50}>105,7 \pm 1,2 \mu \mathrm{g} / \mathrm{mL}\right)$. No entanto, o extrato e demais frações não foram ativos contra esta forma do parasito $\left(\mathrm{CI}_{50}>200 \mu \mathrm{g} / \mathrm{mL}\right.$; Tabela 1).

Ao realizar o cálculo da Concentração Inibitória $50 \%$, verificou-se que o EE e a FA mostraram-se ativas $\left(\mathrm{CI}_{50}=23,87\right.$ $\mu \mathrm{g} / \mathrm{mL} \pm 0,87$ e 18,8 $\pm 0,94$, respectivamente) contra a forma amastigota de $L$. (L.) amazonensis, sendo que a fração FA foi mais ativa que o EE. Enquanto que para as frações FrHEX e FrDCL esta atividade foi moderada $\left(\mathrm{CI}_{50}=143,0 \mu \mathrm{g} / \mathrm{mL} \pm 0,82 \mathrm{e}\right.$ $204,5 \pm 0,71$, respectivamente). As demais frações se mostraram inativas contra esta forma do parasito $\left(\mathrm{CI}_{50}>500 \mu \mathrm{g} / \mathrm{mL}\right.$; Tabela 1).

Tabela 1 - Atividade anti-promastigota e anti-amastigota de Aspidosperma nitidum.

\begin{tabular}{lcc}
\hline Amostras & Promastigota & Amastigota \\
\cline { 2 - 3 } & \multicolumn{2}{c}{$\mathrm{CI}_{50}+\mathrm{DP}(\mu \mathrm{g} / \mathrm{mL})$} \\
\hline EE & $>200$ & $23,87 \pm 0,87$ \\
FN & $>200$ & $>500$ \\
FA & $>200$ & $18,5 \pm 0,94$ \\
FrHEX & $105,7 \pm 1,12$ & $143,0 \pm 0,82$ \\
FrDCL & $>200$ & $204,5 \pm 0,71$ \\
FrAcOEt & $>200$ & $>500$ \\
FrMeOH & $0,06 \pm 0,0020$ & $>500$ \\
AB & & $4,4 \pm 0,9$ \\
\hline
\end{tabular}

CI50 - Concentração inibitória 50\%; DP - Desvio padrão; EE - Extrato etanólico; FA - Fração alcaloídica; FN - Fração de neutros; FrHEX Fração hexano; FrDCL - Fração diclometano; FrAcOEt - Fração acetato de etila; FrMeOH- Fração metanolica; AB- anfotericina B. Fonte: Autores. 


\subsection{Citotoxicidade e seletividade}

A citotoxicidade foi avaliada em macrófagos murinos. O EE mostrou-se menos citotóxico e mais seletivo $\left(\mathrm{CC}_{50}=491,8\right.$ $\pm 1,86$; $\mathrm{SI}=21)$ para a forma amastigota em relação a $\mathrm{FA}\left(\mathrm{CC}_{50}=184,7 \pm 2,5 ; \mathrm{SI}=11\right)$. Enquanto que, a FrHEX apresentou baixa seletividade para esta forma do parasito (IS $=2,2$ ). A FrDCL apresentou seletividade para a forma promastigota superior a 4,7 e para formas amastigotas acima de 2,4 (Tabela 2).

Tabela 2 - Citotoxicidade e índice de seletividade de Aspidosperma nitidum.

\begin{tabular}{lccc}
\hline Amostras & Citotoxicidade & \multicolumn{2}{c}{ Índice de seletividade (IS) } \\
\cline { 2 - 4 } & $\mathrm{CC}_{50} \pm \mathrm{DP}(\mu \mathrm{g} / \mathrm{ml})$ & Promastigota & Amastigota \\
\hline $\mathrm{EE}$ & $491,8 \pm 1,86$ & - & 21 \\
$\mathrm{FN}$ & $209,1 \pm 1,7$ & - & - \\
$\mathrm{FA}$ & $184,7 \pm 2,5$ & - & 11 \\
FrHEX & $308,9 \pm 0,82$ & - & 2,2 \\
FrDCL & $>500$ & $>4,7$ & $>2,4$ \\
FrAcOEt & $>500$ & - & - \\
FrMeOH & $473,0 \pm 0,76$ & - & - \\
$\mathrm{AB}$ & $>100$ & $>1667$ & $>22,7$ \\
\hline
\end{tabular}

$\mathrm{CC}_{50}$ - Concentração citotóxica 50\%; DP - Desvio padrão; EE - Extrato etanólico; FA - Fração alcaloídica; FN - Fração de neutros; FrHEX Fração hexano; FrDCL - Fração diclometano; FrAcOEt - Fração acetato de etila; FrMeOH - Fração metanolica; AB- anfotericina B. Fonte: Autores.

\section{Discussão}

Os rendimentos das frações FrHEX (rendimento $=2,4 \%$ ), FrDCL (rendimento $=8,37 \%$ ), FrAcOEt (rendimento $=$ 18,6 \%) e FrMeOH (rendimento = 38,4 \%), sugere que o extrato etanólico é constituído, principalmente, de substâncias de maior polaridade. $\mathrm{E}$ ao analisar todas as amostras por $\mathrm{CCD}$, verificou-se o predomínio de manchas azuis, quando visualizadas em UV, mas quando estas placas foram reveladas com reagente Dragendorff observou-se manchas castanho-alaranjadas apenas no EE, FA e FrDCL, sugestivas de alcaloides. Estudos químicos anteriores de A. nitidum levaram ao isolamento de alcaloides indólicos (Arndt, et al., 1967; Pereira ${ }^{a}$, et al., 2006; Pereira ${ }^{\text {b }}$ et al., 2006; Nascimento \& Silveira, 2006; Nascimento, et al., 2006; Martins, 2012).

A análise do espectro de RMN de ${ }^{1} \mathrm{H}$ da fração FA demonstrou a presença de sinais sugestivos de alcaloides indólicos, sendo que os deslocamentos químicos em $\delta H$ 7,47, 7,41, 7,36, 7,30, 7,26, 7,19, 7,08, 6,96 e 6,89 foram atribuídos aos hidrogênios do anel aromático do sistema indólico quando comparadas com dados da literatura (Robert, et al, 1983, Verpoorte, et al., 1982, Uchoa, 2006, English \& Williams, 2010, Torres, 2012).

No presente estudo, observou-se que a EE e FA não se mostraram promissores para a forma promastigota, porém foram ativos na forma responsável pela doença (Tabela 1). Indicando que atividade contra promastigotas não confere necessariamente atividade contra amastigota e vice-versa. Ambos os estágios do parasita possuem diferentes características moleculares e bioquímicas, conferindo diferenças de sensibilidade das drogas (Camacho, et al., 2002). O Pentostam, por exemplo, é efetivo contra formas amastigotas, mas não o é para promastigotas de Leishmania spp. (Olliaro \& Brycenton, 
1993). O mesmo comportamento foi observado com o alcaloíde bisbenzilisoquinolinico denominado Faeantina que mostrou fraca atividade contra promastigotas, mas significante atividade contra amastigotas (Camacho, et al., 2002).

A atividade antiamastigota do EE e da FA, provavelmente, está relacionada aos alcaloides, pois nas frações de alcaloides de A.nitidum foram dectectados alcaloides indólicos com características estruturais bem próximas as da desacetilaspidospermina (Martins, 2012) e iombina (Nascimento, 2013). E no extrato etanólico das cascas de A. nitidum já foram isolados os seguintes alcalóides:10-metoxidiidrocorinanteol, corinanteol, heteroioimbina (Arndt, et al., 1967), ácido harmanocarboxílico (Pereira ${ }^{a}$, et al., 2006), 3-metil-harmano carboxílico, diidrocorinanteol (Nascimento \& Silveira, 2006), desidrositsirikina (Nascimento, et al., 2006) e braznitidumina (Pereira ${ }^{\text {b }}$, et al., 2006).

Nas frações obtidas da extração sob refluxo apenas as frações FrHEX e FrDCL mostraram-se ativas contra $L .(L$.) amazonensis, sendo que só a FrDCL mostrou atividade moderada contra as duas formas evolutivas (promastigota e amastigota) de Leishmania (Tabela 1). Observando-se que as frações de menor polaridade obtidas por este método de extração apresentaram maior atividade leishmanicida, podendo indicar que a atividade desta planta esteja relacionada a uma(s) substancia(s) de baixa ou média polaridade.

Ao analisar a placa cromatográfica contendo as FrHEX e FrDCL, observou-se machas azuis, em ambas as frações, quando visualizadas em UV, sendo que quando a placa foi revelada com reativo de Dragendorff, apenas a FrDCL apresentou zona cromatográfica reativa a este reagente, sugerido a presença de alcaloide nesta fração. Este fato sugere, também, que a atividade contra Leishmania da FrDCL pode estar relacionada a presença de alcaloides e indica que os alcaloides podem estar ausentes na fração FrHEX ou que estes poderiam está presentes em baixas concentrações.

Diante do exposto, realizou-se RMN ${ }^{1} \mathrm{H}$ da fração FrHEX e de suas subfrações FrHEX1 e FrHEX2 no sentido de observar ou não sinais sugestivos de alcaloides. Ao analisar os espectros, verificou-se quatro sinais, apenas na subfração FrHEX2, em $\delta H$ 7,60, 7,26, 7,19, 6,90. Ao comparar com dados da literatura, estes sinais correspondem aos hidrogênios do anel benzênico do sistema indólico, tratando-se de alcaloides indólicos (Uchoa, 2006; Torres, 2012). Então, este resultado sugere que os alcaloides podem estar em concentrações muito baixas na fração FrHEX.

Outros estudos vêm demostrando atividade antileishmania dos alcaloides presentes em plantas. Verificou-se a atividade do extrato bruto hexânico de Aspidosperma cuspa contra amastigotas intracelulares de L. amazonensis mostrando um percentual de inibição maior que 50\% nas concentrações de 1, 6, 8, $40 \mu \mathrm{g} / \mathrm{mL}$ (Nunes, 2008). Outro estudo (Delorenzi, et al., 2001) demonstrou que o extrato e frações ricas em alcalóides indólicos tem apresentado atividade em formas promastigota e amastigota em L. amazonensis. A fração alcaloídica obtida das cascas do caule de A. ramiflorum e substâncias puras (ramiflorina A e B) mostraram-se ativas contra as formas promastigotas de L. braziliensis e L. amazonensis, sendo essa atividade maior contra L. amazonensis (Tanaka, et al., 2007; Ferreira, et al., 2004).

Em relação a citotoxicidade do EE, pode-se sugerir que este apresente um baixo potencial citotóxico (Tabela 2) contra macrófagos de camundongo BALB/c. Em outras pesquisas desenvolvidas com espécies do gênero Aspidosperma, observa-se que as substâncias obtidas destas plantas quando testadas contra diferentes tipos celulares apresentam baixa ou moderada citotoxicidade ou não se mostram citotóxicas, conforme podemos observar na literatura citada a seguir. O Ext.EtOH (extrato etanolico) de A. nitidum e suas frações FA e FN não apresentaram citotoxicidade para células hepáticas $\left(\mathrm{CC}_{50}=410,65 \mu \mathrm{g} / \mathrm{mL}\right.$, $376,73 \mu \mathrm{g} / \mathrm{mL}$ e $452,53 \mu \mathrm{g} / \mathrm{mL}$, respectivamente; Martins, 2012). O extrato hidroetanólico de A. excelsum não ocasionou redução da viabilidade celular de fibroblastos murinos, indicando não ser citotóxico para esta linhagem celular $\left(\mathrm{CC}_{50}>6250\right.$ $\mu \mathrm{g} / \mathrm{mL}$ ) e sua fração alcaloídica C2 apresentou pequena citotoxicidade nas concentrações superiores a $800 \mu \mathrm{g} / \mathrm{mL}$ (Gomes, 2011). Em outro estudo, o extrato etanólico de Aspidosperma parvifolium demonstrou baixa citotoxicidade em culturas de células VERO $\left(100<\mathrm{CC}_{50}<500 \mu \mathrm{g} / \mathrm{mL}\right.$; Dolabela, 2007). 
A FA, apesar de apresentar uma menor $\mathrm{CI}_{50}$ para a forma amastigota, apresentou um maior potencial citotóxico que o EE (Tabelas 1 e 2), sugerindo que o aumento do teor de alcaloides pode estar relacionado a este fato. A fração de acetato de etila das tinturas de Schinus terebinthifolius e Solidago chilensis obtiveram maior percentual de atividade citotóxica apresentando 97,2\% e 98,5\%, respectivamente em comparação ao extrato etanólico destas espécies vegetais. Identificando-se maior teor de compostos fenólicos como flavonóides nas tinturas. Destacando-se que as tinturas de $S$. terebinthifolius e $S$. chilensis são usadas via oral, porém em baixíssimas concentrações, sem riscos de toxicidade (Silva, 2018).

A não identificação do(s) possível(is) alcaloide(s) envolvido(s) na atividade leishmanicida foi um fator limitante neste estudo, pois não conseguimos determinar a substância responsável por esta atividade. Estudos envolvendo métodos espectrométricos de ressonância magnética nuclear de hidrogênio e de carbono 13 (RMN ${ }^{1} \mathrm{H} \mathrm{e}{ }^{13} \mathrm{C}$ ), 1D e 2D e espectrometria de massa (EM). precisam ser realizados visando a elucidação deste provável alcaloide.

\section{Conclusão}

Estes resultados sugerem que, realmente, o EE obtido das cascas de Aspidoperma nitidum é promissor como leishmanicida, requerendo estudos químicos adicionais para identificar a substância responsável pela atividade. Além disso, estes resultados corroboram com os relatos de uso popular da planta, levando a inferir sobre o potencial do extrato para obtenção de novas entidades químicas contra $L$. (L.) amazonensis.

A elucidação estrutural do possível alcaloide responsável pela atividade leishmanicida e avaliação das alterações morfológicas em Leishmania (L.) amazonensis ocasionadas pelas amostras ativas serão os próximos passos a serem dados nesta pesquisa.

\section{Agradecimentos}

Os autores agradecem as agências brasileiras como Conselho Nacional de Desenvolvimento Científico e Tecnológico (CNPq), Comissão de Aperfeiçoamento de Pessoal de Nível Superior (CAPES) e a Fundação Amazônia de Amparo a Estudos e Pesquisas (FAPESPA) pelo suporte financeiro a este estudo e a professora Dra. Marlia Regina Coelho-Ferreira, pesquisadora do Museu Paraense Emílio Goeldi, (Belém, PA) pela identificação botânica da planta.

\section{Referências}

Arndt, R. R., Brown, S. H., Ling, N. C., Roller, P., Djerassi, C., Ferreira, J. M., Gilbert, B., Miranda, E. C., Flores, S. E., Duarte, A. P., \& Carrazzoni, E. P (1967). Alkaloid studies- LVIII: The alkaloids of six Aspidosperma species. Phytochemistry, 6, 1653- 1658. doi.org/10.1016/S0031-9422(00)82898-8.

Blackmore, C. G., McNaughton, P. A., \& Veen, H. W. V. (2001). Multidrug transporters in prokaryotic and eukaryotic cells: physiological functions and transport mechanisms. Molecular Membrane Biology, 18, 97-103. 10.1080/09687680010030200.

Camacho, M. D. R., Phillipson, J. D., Croft, S. L., Rock, P., Marshall, S. J., Schiff Jr, P. L. (2002). In vitro activity of Triclisia patens and some Bisbenzylisoquinoline Alkaloids against Leishmania donovani and Trypanosoma brucei brucei. Phytotherapy Research, 16, 432-436. 10.1002/ptr.929.

Chulay, J. D., Spencer, H. C., \& Mugambi, M. (1985). Electrocardiographic changes during treatment of leishmaniasis with pentavalent antimony (sodium stibogluconate). American Journal Tropical Medicine and Hygiene, 34, 702-709. 10.4269/ajtmh.1985.34.702.

Chulay, J. D., Fleckenstein, L., \& Smith, D. H. (1988). Phamacokinetics of antimony during treatment of visceral leishmaniasis with sodium stibogluconate or meglumine antimoniate. Transactions of the Royal Society of Tropical Medicine and Hygiene, 82, 69-72. https://pubmed.ncbi.nlm.nih.gov/2845611/.

Croft, S. L., \& Yardley, V. (2002). Chemotherapy of leishmaniasis. Current Pharmaceutical Design, 8(4), 319-342. 10.2174/1381612023396258.

Delorenzi, J. C., Attias, M., Gattass, C. R., Andrade, M., Rezende, C., Pinto, A. C., Henriques, A. T., Bou-Habib, D. C., \& Saraiva, E. M. B. (2001). Antileishmanial activity of an indole alkaloid from Peschiera australis. Antimicrobial Agents and Chemotherapy, 45(5), 1349-1345. 10.1128/AAC.45.5.13491354.2001.

Dolabela, M. F. (2007). Atividade antiplasmódica e citotoxidade de Esenbeckia febifuga (A.St-hil.) Juss. ex Mart. (Rutaceae) e de espécies do gênero Aspidosperma (Apocynaceae) Tese (doutorado). Faculdade de farmácia, Universidade Federal de Minas Gerais, Belo Horizonte, Brazil. 
English, B. J., \& Williams, R. M. (2010). A divergent strategy for the synthesis of secologanin derived natural product. Journal of Organic Chemistry Research, 75, 7869-7876. doi.org/10.1021/jo101775n.

Ferreira, I. C. P., Lonardoni, M. V. C., Machado, G. M. C., Leon, L. L., Gobbi Filho, L., Pinto, L. H. B., \& Oliveira, A. J. B. (2004). Anti-leishmanial activity of alkaloidal extract from Aspidosperma ramiflorum. Memórias do Instituto Oswaldo Cruz, 99(3), 325-327. doi.org/10.1590/S0074-02762004000300015.

Franke, E. D., Wignall, S., Cruz, M. E., Rosales, E., Tovar, A. A., Lucas, C. M., Alejando, Llanos-Cuentas, M. D., \& Berman, J. D. (1990). Efficacy and toxicity of sodium stibogluconate for mucosal leishmaniasis. Annals of Internal Medicine, 113, 934-40. 10.7326/0003-4819-113-12-934.

Gomes, L. F. S. (2011). Abordagem fitoquímica, determinação da atividade antiplasmódica in vitro e avaliação preliminar da toxicidade do extrato hidroetánolico das cascas de Aspidosperma excelsum Benth (Apocynaceae). Dissertação (Mestrado). Faculdade de Farmácia, Universidade Federal do Pará, Belém, Brasil.

Leslie, E., Deeleyb, R. G., \& Cole, S. P. C. (2005). Multidrug resistance proteins: role of P-glycoprotein, MRP1, MRP2 and BCRP (ABCG2) in tissue defense. Toxicology Applied Pharmacology, 204, 216-237. 10.1016/j.taap.2004.10.012.

Lima, E. B., Porto, C., Motta, J. O. C., \& Sampaio, R. N. R. (2007). Tratamento da leishmaniose tegumentar americana. Anais Brasileiros de Dermatologia, 82(2), 111-124. doi.org/10.1590/S0365-05962007000200002.

Marsden, P. D. (1994). Mucosal leishmaniasis due to Leishmania (viannia) braziliensis in Três Braços, Bahia-Brazil. Revista da Sociedade Brasileira de Medicina Tropical, 27(2), 93-101. doi.org/10.1590/S0037-86821994000200007.

Martins, T. M. (2012). Estudo farmacognóstico, fitoquímico e atividades biológicas de Aspidosperma nitidum Benth. Ex Mull. Arg. Dissertação (mestrado). Faculdade de Farmácia, Universidade Federal do Pará, Belém, Brasil.

Mosmann, T. (1983). Rapid Colorimetric assay for cellular growth and survival: application to proliferation and cytotoxicity assays. Journal of Immunological Methods, 65, 55-63. 10.1016/0022-1759(83)90303-4.

Mota, E. F., Rosario, D. M., Veiga, A. S. S., Brasil, D. S. B., Silveira, F. T., \& Dolabela, M. F. (2015). Biological activities of Croton palanostigma Klotzsch. Pharmacognosy Magazine, 11(43), 1-6. 10.4103/0973-1296.176109.

Naiff, M. F., Cupolillo, E., Naiff, R. D., Momen, H., Barret, T. V., \& Grimaldi Jr, G. (1999). Leishmaniose tegumentar americana na Amazônia: distribuição geográfica dos agentes etiológicos na região. Revista da Sociedade Brasileira de Medicina Tropical, 32(1), 1-243.

Nascimento, P. C., \& Silveira, E. R. (2006). Alcalóides indólicos de Aspidosperma nitidum. In: Reunião Anual da Sociedade Brasileira de Química, 31, Águas de Lindóia. Resumo. São Paulo. http://sec.sbq.org.br/cdrom/31ra/resumos/T1901-1.pdf.

Nascimento, P. C., Araújo, R. M., \& Silveira, E. R. (2006). Aplicação da CLAE na análise fitoquímica de Aspidosperma nitidum. In: Reunião Anual da Sociedade Brasileira de Química, 29., Águas de Lindóia. Resumo. São Paulo, 2006. http://sec.sbq.org.br/cdrom/32ra/resumos/T2285-2.pdf.

Nascimento, S. M. (2013). Investigação fitoquímica e das atividades antioxidante e antiparasitária do extrato e frações de Aspidosperma excelsum Benth. Dissertação (Mestrado). Faculdade de Farmácia, Universidade Federal do Pará, Belém, Brasil.

Neves, L. O., Talhari, A. C., Gadelha, E. P. N., Silva Júnior, R. M., Guerra, J. A. O., Ferreira, L. C. L., \& Talhari, S. (2011). Estudo Clínico Randomizado comparando antimoniato de meglumina, pentamidina e anfotericina B para o tratamento da Leishmaniose cutânea ocasionada por Leishmania guyanensis. Anais Brasileiros de Dermatologia, 86(6), 1092-1101. 10.1590/S0365-05962011000600005.

Ngure, P. K., Tonui, W. K., Ingonga, J., Mutai, C., Kigondu, E., Ng'ang'a, Z., Rukunga, G., \& Kimutai, A. (2009). In vitro antileishmanial activity of extracts of Warburgia ugandensis (Canellaceae), a Kenyan medicinal plant. Journal of Medicinal Plants Research, 3(2), 61-66. 10.5897/JMPR.9000739.

Nunes, R. K. (2008). Avaliação da atividade tripanocida e leishmanicida de produtos naturais da flora mato-grossense. Monografia (Trabalho de conclusão de curso). Departamento de Microbiologia e Parasitologia, Universidade Federal de Santa Catarina, Florianópolis, Brasil. https://repositorio.ufsc.br/xmlui/handle/123456789/132885.

Olliaro, P. L., \& Bryceson, A. D. M. (1993). Pratical progress and new drugs for changing patterns of leishmaniasis. Parasitology. Today, 9(9), 323-328. $10.1016 / 0169-4758(93) 90231-4$.

Padrón-Nieves, M., \& Ponte-Sucre, A. (2015). Marcadores de resistencia en Leishmania: Susceptibilidad in vitro a drogas leishmanicidas vs retención de calceina en aislados de pacientes venezolanos con Leishmaniasis Cutánea Difusa. Archivos Venezolanos de Farmacología y Terapéutica, 34(4), 53-57. http://ve.scielo.org/scielo.php?script=sci_arttext\&pid.

Pereira $^{a}$, M. M., Souza Júnior, S. N., Alcântara, A. F. C., Piló-Veloso, D., Alves, R. B., Machado, P.O., Azevedo, A. O., Moreira, F. H., Castro, M. S. A., \& Raslan, D. S. Constituintes químicos e estudo biológico de Aspidosperma nitidum (Apocynaceae). Revista Brasileira de Plantas Medicinais, 8(3), 1-8. https://www1.ibb.unesp.br/Home/Departamentos/Botanica/RBPMRevistaBrasileiradePlantasMedicinais/artigo1_v8_n3.pdf.

Pereirab $^{\text {b }}$ M. M., Alcântara, A. F. C., Piló-Veloso, D., \& Raslan, D. S. (2006). NMR structural analysis of Braznitidumine: a new indole alkaloid with 1,2,9triazabicyclo[7.2.1] system, isolated from Aspidosperma nitidum (Apocynaceae). Journal of the Brazilian Chemical Society, 17(7), 1274-1280. $10.1590 / \mathrm{S} 0103-50532006000700012$.

Reimão, J. Q. (2009). Estudo da atividade anti-leishmania de compostos de invertebrados marinhos brasileiros. Dissertação (mestrado). Coordenadoria de Controle de Doenças da Secretaria de Estado da Saúde de São Paulo, São Paulo, Brasil.

Robert, G. M. T., Ahond, A., Poupat, C., \& Potie, P. (1983). Aspidosperma de Guyane: Alcaloides de Aspidosperma Marcgravianum. Journal of Natural Products, 46(5), 694-707. 10.1021/np50029a018. 
Research, Society and Development, v. 10, n. 2, e50210212646, 2021

(CC BY 4.0) | ISSN 2525-3409 | DOI: http://dx.doi.org/10.33448/rsd-v10i2.12646

Silva-Silva, J.V., Brigido, H. P. C., Albuquerque, K. C. O., Carvalho, J. M., Reis, J. F., Faria, L. V., Coelho-Ferreira, M. R., Silveira, F.T., Carneiro, A. S., Percário, S., Marinho, A. M. R., \& Dolabela, M. F. (2019). Flavopereirine-An alkaloid derived from Geissospermum vellosii-presents leishmanicidal activity in vitro. Molecules, 24(785), 1-13. 10.3390/molecules24040785.

Silva, M. G. F. 2018. Estudo da atividade antioxidante e citotóxica do extrato etanólico, frações e tinturas comerciais de Solidago chilensis Meyen e Schinus terebinthifolius Raddi obtidos na região metropolitana do Recife-PE. Dissertação (mestrado). Departamento de Histologia, Universidade Federal de Pernambuco, Recife, Brasil. https://repositorio.ufpe.br/handle/123456789/30741

Tanaka, J. C. A., Silva, C. C., Ferreira, I. C. P., Machado, G. M. C., Leonc, L. L., \& Oliveira, A. J. B. (2007). Antileishmanial activity of indole alkaloids from Aspidosperma ramiflorum. Phytomedicine, 14, 377-380. 10.1016/j.phymed.2006.09.002.

Torres, Z. E. S. (2012). Contribuição ao conhecimento químico de plantas do nordeste do Brasil: Aspidosperma ulei Markgr. Tese (doutorado). Departamento de Química Orgânica e Inorgânica, Universidade Federal do Ceará, Fortaleza, Brasil.

Uchoa, D. E. A. (2006). Aplicação de técnicas contemporâneas de ressonância magnética nuclear no estudo fitoquímico de Aspidosperma ulei. Dissertação (mestrado). Departamento de Química Orgânica e Inorgânica, Universidade Federal do Ceará, Fortaleza, Brasil.

Vale, V.V., Vilhena, T. C., Trindade, R. C. S., Ferreira, M. R. C., Percário, S., Soares, L. F., Pereira, W. L. A., Brandão, G. C, Oliveira, A. B., Dolabela, M. F. \& Vasconcelos, F. (2015). Anti-malarial activity and toxicity assessment of Himatanthus articulatus, a plant used to treat malaria in the Brazilian Amazon. Malaria Journal, 14(132), 1-10. 10.1186/s12936-015-0643-1.

Verpoorte, R., Ruigrok, C. L. M., \& Svendsen, A. B. (1982). Medicinal Plants of Surinam II: Antimicrobial Active Alkaloids from Aspidosperma marcgravianum. Journal of Medicinal Plant Research, 46, 149-152. europepmc.org/article/med/7178295.

WHO (World Health Organization). (2019). Global Health Observatory (GHO) Data. https://www.who.int/gho/neglected_diseases/leishmaniasis/en/. 